\title{
Pancreatic Cyst
}

National Cancer Institute

\section{Source}

National Cancer Institute. Pancreatic Cyst. NCI Thesaurus. Code C3304.

A fluid-filled, epithelium-lined cyst located in the pancreas. 